\title{
AS ÁRIAS DE MEMÓRIA DAS VELHAS AMAS DE LEITE DA ÓPERA VENEZIANA DO SÉCULO XVII
}

\author{
Ligiana Costa
}

\section{RESUMO:}

Entre os importante destaque. Durante um século de sua presença nos palcos venezianos foram 114 personagens. Umas das marcantes características desta tipologia de personagens é a nostalgia do passado que se concretiza no que chamamos aqui de árias de memória. Ao se lembrar de sua juventude a ama de leite provoca em sua jovem protegida o desejo pelo carpe diem, apoiada pelo conceito de memento mori, colaborando indiretamente para os desenlaces dramatúrgicos. Este artigo faz um percurso por algumas destas árias e das diferentes tipologias internas deste topos.topoi do nascente teatro de ópera veneziano o personagem da velha ama de leite cômica aparece com

\section{PALAVRAS-CHAVE:}

ária de memória; ama de leite; ópera veneziana; século XVII.

\section{ABSTRACT:}

Among the topoi of the emerging Venetian opera the character of the old comic wet nurse appears with important highlight. During a century in Venetian stages we have listed 114 characters. One of the striking features of this dramatic type is the nostalgia summed up in what we call here the memory arias. By remembering her youth the wet nurse influence on her protected young lady desire for carpe diem, rooted on the concept of memento mori, contributing indirectly to the dramaturgical outcomes. This article is a journey through some of these arias and different types of these internal topoi. 


\section{KEYWORDS:}

memory airs, wet nurse, venetian opera, seventeenth century.

Este artigo tem como origem a tese de doutorado defendida pela autora em 2008 pelas universidades François Rabelais de Tours e Statale de Miláo sobre o corpus de personagens de velhas amas de leite cômicas da ópera veneziana do século XVII. Ao se estabelecer os eventos fundamentais para o nascimento da ópera, costuma-se elencar as experiências florentinas, as mantuanas, as romanas e a posterior chegada da ópera comercial em Veneza em 1637. Neste trabalho defendemos a existência de mais um pilar para a concretização da ópera como gênero definitivo: a inserção de personagens baixos nas tramas dos libretos. Sáo pajens, servas, mensageiros e outros personagens ditos "baixos" que passam a compor, ao lado de semideuses, pastores e heróis, as novas tramas operísticas. $\mathrm{O}$ primeiro destes personagens a ter uma aparição em cena, já na segunda ópera encenada em Veneza, é a velha governanta Scarabea da ópera La Maga Fulminata da dupla Francesco Manelli e Benedetto Ferrari.

Durante o século XVII esta tipologia de personagens ganha tamanha importância, que se torna raríssimo um libreto veneziano sem a presença de uma velha ama de leite, que ao longo do século somam 114. Estas velhas amas de leite cômicas, sempre representadas en travesti, sáo descendentes tanto de máscaras cômicas da Commedia dell'Arte (como é o caso da máscara Franceschina) quanto das velhas amas de leite em função de duplo dos heróis trágicos clássicos. Algumas características quase fixas podem ser encontradas neste grupo de personagens, como um inesgotável desejo sexual que contrasta com suas realidades decrépitas (o que proporcionava às tramas um comic relief de origem grotesca), a relaçáo de intimidade e confidencialidade com os personagens centrais das tramas, entre outros. Neste artigo trataremos de um topos específico destes personagens: as árias de memória. Em cena, as velhas se recordam da juventude e usam deste recurso para reforçar o discurso do carpe diem e do memento mori, reconhecendo a brevidade e a caducidade da vida, mas, diferentemente do repertório madrigalístico e monódico que trata este tema, estes personagens tentam oferecer soluçóes e alívio a esta realidade 
imutável. A noção de Vanitas se combina então com o horaciano Carpe Diem, chegando-se à conclusão: a única saída para a certeza da finitude é aproveitar do momento presente, sendo o momento presente a juventude (no caso das árias endereçadas às jovens protegidas) ou a própria velhice (em forma de tentativas de conquistas amorosas ou de imersão nas memórias do passado).

\section{“LA MEMORIA È FLAGELLO”}

Um caso que pode nos dar, de forma imediata, uma noçáo da complexidade destes personagens é o casal de "vecchie abitanti in capanna" do libretto L'Helena rapita da Theseo (1653) de Giacomo Badoaro, com musica perdida de Francesco Cavalli. Na primeira cena em que aparecem os dois personagens o autor qualifica as duas velhas: "Nisa vecchia cadente, e Riffea manco vecchia”. O diálogo entre as duas velhas em versos sciolti se constrói em torno da contraposição das teses sustentadas por elas. As duas são conscientes da decrepitude que lhes aguarda, mas Nisa tem uma visão puramente negativa e por isso mais estritamente ligada ao conceito de vanitas em relação a Riffea que tenta gozar do presente graças às lembranças do passado, um carpe diem baseado na memória, "aproveite o momento presente para se lembrar". Riffea diz: "Hor dei passati dì / pur godo allhor che penso" enquanto Nisa sustenta que a "memoria è flagello". O diálogo inteiro é elucidativo destes dois modelos filosóficos:

[I/2]

NISA

Stanca son di portar ceneri, et ossa

Riffea sorella amara

questa machina antica,

che poco basta a sostener natura

tremante, e mal sicuta

varca tombe, e sepolcri,

e con si picciol legno

disperdo l'hore in misurar la fossa.

Stanca son di portar ceneri, et ossa.

RIFFEA

Corronsi dietro ò Nisa 
la tua cadente, e la mia vecchia etade; ma tu vivi dolente ogn'hora mesta sei io rubbo dolcemente al tempo, et alla morte i giorni miei. Fuggiamo sorella la noia, e 'l martir; È mal esser vecchia ma peggio è morir.

NISA

A questa mia decrepità cadente assai maggior fatica

è 'l viver del morire.

Con mille affanni, e doglie compro quest'hore corte e con un sol sospir pago la morte.

RIFFEA

Col cangiarsi dei dì non che degl'anni si cangiano i diletti scorre l'humana voglia variabile, e mista se si perde un piacer un sen s'acquista. Ogni età seco porta il suo goder pur, che lieto si viva ogni cosa è piacer. Le delizie del cor mutano tempre, e quel, ch'oggi gradì non piace sempre. Giovine, e bella sì hebbi diletti al senso, hor dei passati dì pur godo all'hor, che penso.

Così l'età cangiata ha doppia gloria gode pria le bellezza hor la memoria.

NISA

Mal discorri sorella ciò, che di ben passò resta in affanno se l'utile rammenti hor trovi il danno; che del goduto bene, e del perduto bello i pensieri son pene la memoria è flagello. 


\section{RIFFEA}

$\mathrm{O}$ che gioia il pensar

nei trionfi passati

l'amoroso pennar

di mille innamorati

NISA

O che duolo il soffrir

dietro le cose andare

un sempre van desir

delle gioie passate

\section{RIFFEA}

Non mi torrà

la fredda età

con i rigori sui

ch'al fin non possa dir io bella fui

NISA

Stolta Riffea sei tu;

se fosti fresca, e bella, hor non sei più

è vano pregio in cominciar da su.

\section{[TRADUÇÁO]}

[I/2]

NISA

Cansada estou de carregar cinzas, e ossos

Riffea, irmã amarga

Esta máquina antiga,

que mal consegue sustentar a natureza

trêmula, e insegura

atravessa tombas, e sepulcros,

e com pequenissima vara

passo horas medindo o fosso.

Cansada estou de carregar cinzas, e ossos.

\section{RIFFEA}

Elas correm atrás uma da outra, oh Nisa A tua decadente, e a minha velha idade; mas tu vives dolente

estás sempre triste

eu roubo docemente

ao tempo, e à morte os meus dias.

Fujamos irmá 
Do tédio, e do martírio;

Ruim ser velha

Mas pior é morrer.

NISA

A esta minha decrepitude decadente

Assaz maior fadiga

é viver que morrer.

Com mil angústias, e dores

compro estas horas curtas

e com um único suspiro pago a morte.

\section{RIFFEA}

Com o mudar dos dias e dos anos

Se modificam os prazeres

A vontade humana segue

Variável e mista

Ao se perder um prazer, outro se conquista.

Cada idade traz consigo o seu gozo

Desde que se viva feliz

Tudo è prazeroso.

As delícias do coração mutam tempras,

e o que hoje agrada, não sempre agradou.

Jovem, e bela sim

Tive prazeres nos sentidos,

agora gozo

ao pensar nos dias passados.

Assim a idade transformada tem glória dupla

Gozou primeiro a beleza, agora a memória.

NISA

Mal discorres, irmã

Aquilo que de bom passou fica na angústia se a lembrança útil agora encontra o dano ; pois do bem desfrutado,

e da beleza perdida

os pensamentos são pesares

a memória é flagelo.

RIFFEA

Oh que alegria pensar

Nos triunfos passados

$\mathrm{O}$ amoroso penar

De mil apaixonados 
NISA

Oh que dor sofrer

Atrás das coisas andar

Um sempre vão desejo

Das alegrias passadas

\section{RIFFEA}

Não me terá

A fria idade

Com seus rigores

Que ao final não possa dizer 'eu fui bela'

NISA

Éres boba, Riffea;

se fostes fresca, e bela, agora não o és mais

é uma qualidade vã começar pelo alto.

Tab. 1: BADOARO/CAVALLI, 1653, cena I,2, Veneza, Michiel Miloco.

A constatação da decrepitude é normalmente acompanhada pela lembrança de uma juventude feliz e sexualmente ativa; a grande parte deste corpus se aproxima mais de Riffea que de Nisa. Estes dois momentos convivem nas árias que aqui denominamos "árias de memória". São numerosos os exemplos de árias estruturadas desta maneira: um primeiro momento (A) em modo de lamento sério e um segundo momento (B) de lembranças da juventude e dos amores passados. Esta forma poética pode ter seus desdobramentos musicais - nos casos de árias bipartidas -, mas pode ser usada em árias estróficas, sem mudanças da estrutura musical. Este é o caso da aria de Delfa, ama de leite na ópera Giasone de Cicognini/Cavalli, encenada pela primeira vez no teatro San Cassiano em 1648. No caso desta ária, a estrutura se faz um pouco mais complexa pois as duas estrofes possuem já internamente um momento contrastante poeticamente bem claro e explicitado pela conjunção adversativa "ma", que musicalmente se explicita com uma passagem em três antecipada por um pequeno recitativo. Ou seja: o passar do tempo (como o personagem chama "o mar eterno de memória”) não é tão ruim, mas o presente $\mathrm{e}$ a atual possibilidade de amar é ainda melhor. Vejamos como isto se dá na partitura : 


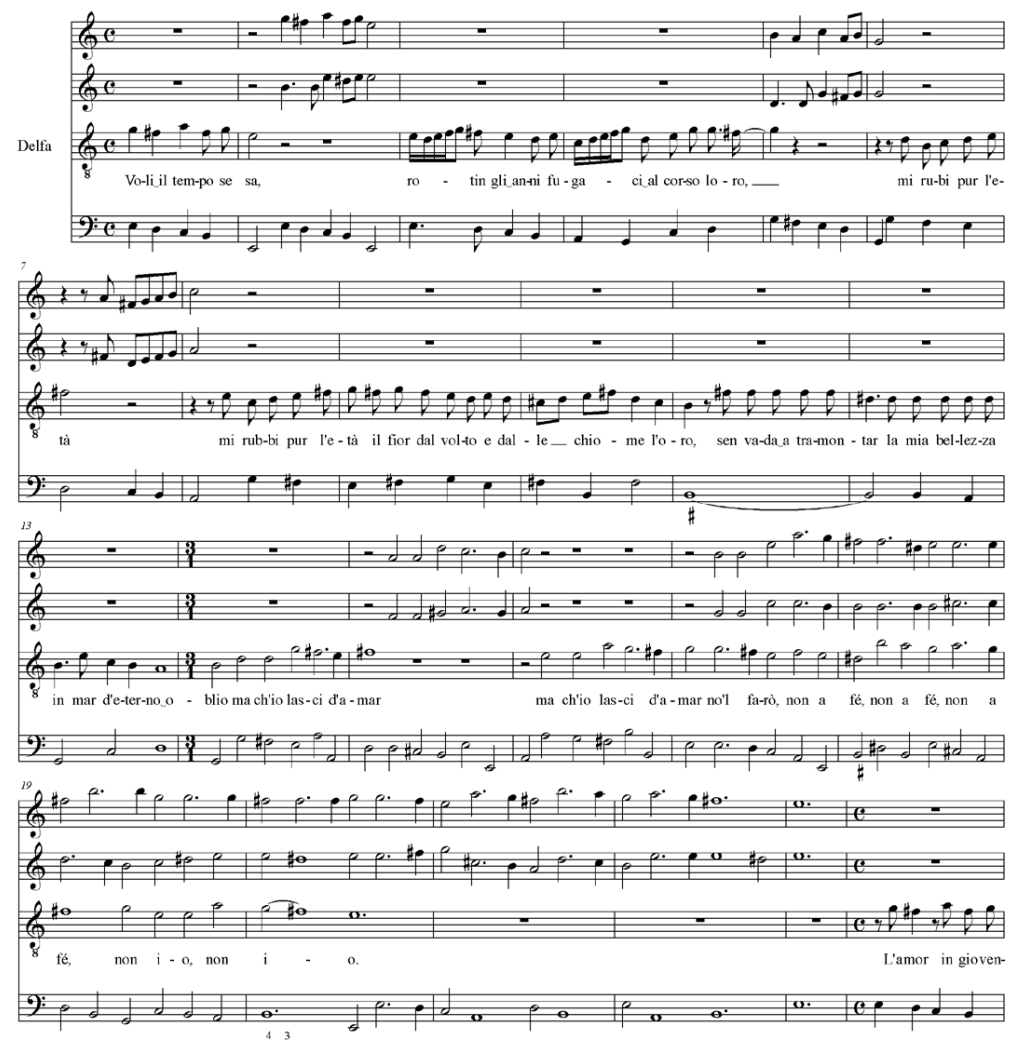

Fig. 1: CICOGNINI/CAVALLI, Giasone, I/8, Contarini It. IV, 363 (=9887), C. $39 \mathrm{~V}-$ C. $42 \mathrm{~V}$.

O modo mais comum de aceitar a própria velhice e suportar suas consequências é através das lembranças do passado e a constante atividade da memória. As imagens do passado se tornam fonte principal de vida e, do ponto de vista dramatúrgico, representam a possibilidade de jogar com diversos tempos em uma mesma ação e aprofundar a noçáo de "ridículo" graças ao contraste entre os luxuriosos acontecimentos narrados e a realidade grotesca da açáo presente. Se as tentativas de sedução amorosa - em muitos casos inclusive com tentativas constrangedoras de suborno financeiro - são quase sempre frustradas o apagamento ocorre através da evocaçáo de um passado pleno de muitos amantes e apaixonados. A primeira velha desta sequência de personagens que é o nosso corpus, a velha Scarabea da ópera La maga fulminata, na terceira estrofe de sua ária já coloca a questão da memoria, nos mostrando a origem musical deste topos. 
Possa morir, se settant'anni fa,

preda, e diletto

mezz'il mondo non fù di mia beltà;

hor l'ingrataccio

mi dà di calcio, come fossi un straccio.

$\mathrm{Al}$ suo dispetto,

se ben mi par decrepità sorella,

io son pur tra le vecchie la più bella.

\section{[TRADUÇÃO]}

3.

Que eu possa morrer, se setenta anos atrás,

Presa e desejo

Meio mundo não foi de minha beleza;

Agora o ingratíssimo

Me dá chutes, como se eu fosse um trapo.

Para seu governo,

Se a decrepitude parece ser minha irmã,

Eu sou, entre as velhas, a mais bela.

Tabela 2: FERRARI/MANELLI, La Maga Fulminata in Poesie drammatiche di Benedetto Ferrari della Tiorba, Milano, Ramellatti Gio.Piero, 1644.

O passado como algo digno de ser lembrado em contraste com o presente decrepito é claramente representado na ária da velha Erisbe na ópera Artemisia de Nicoló Minato e Francesco Cavalli, na cena I/11, por uma descida melódica, uma catabasis:

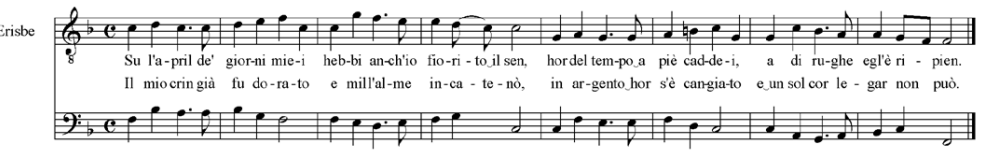

Fig. 2: MINATO/ CAVALLI, Erisbe, I/11, Contarini It. IV, 352 (=9876), I/11, C. $23 \mathrm{~V}-$ C.24R

\section{CONSELHOS}

A função dramática destas árias nas tramas operísticas é a de persuadir as jovens a viverem experiências amorosas com a urgência de quem sabe os limites do tempo. A lembrança do passado combinada com a concretizaçáo viva da passagem do tempo (a presença das velhas) serve como fórmula retóri- 
ca para o doutrinamento às jovens tuteladas pelas velhas. A fórmula é clara: eu me lembro de meu passado, eu te mostro meu presente, eu te convenço a aproveitar suas possibilidades.

Em diversos casos, as velhas chegam a sugerir que, frente à dificuldade da escolha entre os vários possíveis amantes, as jovens tenham vários. Assim sugere uma das mais notáveis amas de leite do nosso corpus, Arnalta, a nutrice de Poppea em um recitativo (I/11), que, por mais moralista que pareça ser durante a ação, confessa em um diálogo com Ottone ter vivido um passado pleno de amantes:

Infelice ragazzo!

Mi move a compassion il miserello;

Poppea non ha cervello

a non gl'aver pietà,

quand'ero in altra età

non volevo gl'amanti

in lacrime distrutti,

per compassion gli contentavo tutti.

\section{[TRADUÇÃO]}

Rapaz infeliz!

Me move à compaixão o pobrezinho; Poppea não tem cérebro

Não lhe tendo piedade,

quando eu tinha outra idade

não queria deixar os amantes

chorarem destruídos

por compaixão contentava todos.

Tabela 3 BUSENELLO/MONTEVERDI, I/11, L'Incoronatione di Poppea, A. Giuliani, Veneza, 1656.

É a compaixão pelos amantes em sofrimento que move também Birena da ópera Marcello in Siracusa de Noris e Boretti na ária cantada na cena III/6. Birena utiliza uma alusão aos olhos lacrimosos dos homens que a desejavam quando ela, jovem, tinha ainda os lábios "vermelhos" (vermiglie) e desloca o adjetivo "umidozinho" (humidetto) ao sujeito "lábios" (labbra), proporciando assim um duplo sentido extremamente erótico que faz referência direta ao desejo feminino: 


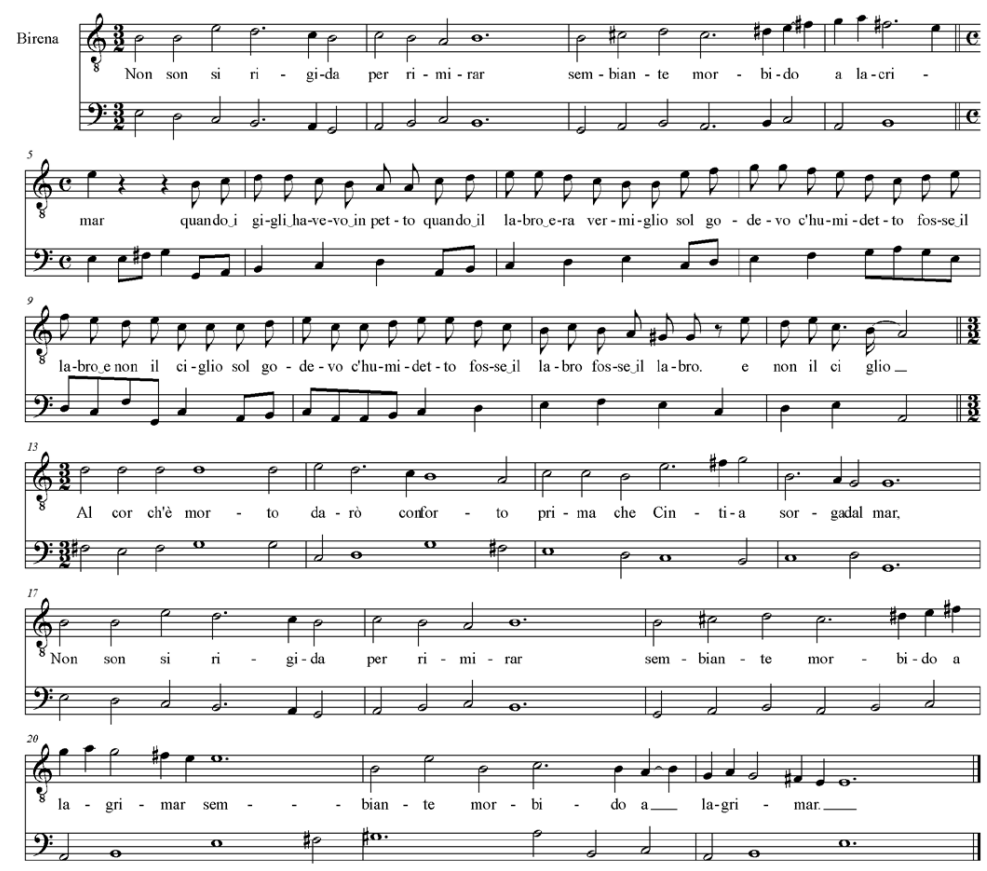

Fig. 3: NORIS/BORETTI, Marcello in Siracusa, III/6, Contarini It. IV, 434 (=9958) C.96 V - C. 97 R.

No Orfeo de Aureli e Sartori a velha ama de leite Erinda fica sozinha em cena depois de ter tentado, sem muito sucesso, explicitar para Euridice as intençóes amorosas de Aristeo para com ela ("EURIDICE: Io non t'indendo a fe / ERINDA: Molto semplice sei”) . Uma vez que Euridice parte, a velha faz uma espécie de resumo da situação dramática em um recitativo e prossegue com a ária (I/4) na qual se arrepende de não ter desfrutado de muitos amantes na juventude:

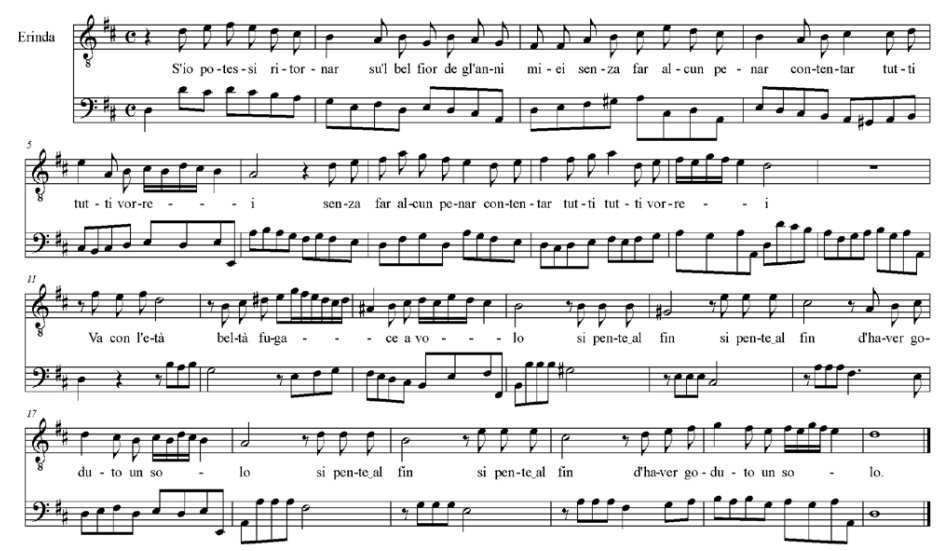

Fig. 4: AURELI/SARTORI, Orfeo, I/4, Contarini It.IV,443 (9967) 
Em contraponto à posição das velhas, observando a passagem do tempo como uma conquista e náo um suplício, estáo os jovens pajens. Assim como o futuro Cherubino, os pajens louvam a passagem do tempo e de suas consequências físicas, como a possibilidade do gozo físico. Eudemo, da ópera $\mathrm{La}$ Caduta di Elio Seiano de Nicolò Minato e Sartorio de 1667, pede que o tempo passe rapidamente para que chegue logo a idade em que poderá gozar dos frutos do amor. Na mesma cena (III/14), que acaba por se tornar icônica desde topos, a velha Plancina (depois de adormentado Eudemo) faz a resposta ao discurso do jovem, lamentando sua velha idade:

\section{EUDEMO}

Hore volate, fuggite o dì, sì che grande anch'io diventi, e contenti poi colei ch'ho nel pensiero perch'io son, a dir il vero troppo picciolo così.

Hore ecc.

Anni correte, deh vieni età, sarò forse all'hor gradito, nel schernito qual fanciul vano, e leggiero, perch'io sono, a dir il vero troppo picciolo così.

Hore ecc.

Germanico non viene, et io di sonno moro.

E che sarebbe se cedessi alquanto

a dolce oblio profondo?

Non caderebbe il mondo. sede e s'addormenta

\section{PLANCINA}

Crin d'argento, senso lento è gran martir. Stan con gl'anni solo affanni e non gioir. 


\section{[TRADUÇÃO]}

\section{EUDEMO}

Horas voem, fujam dias, para que grande eu também me torne e contente, entáo, aquela que tenho no pensamento porque eu sou, na realidade, pequeno demais assim.

Horas etc.

Anos corram, venha idade, serei talvez então aceito, e não zombado como criança vã e leviana porque eu sou, na realidade, pequeno demais assim.

Horas etc

Germanico não vem, e eu de sono morro.

E o que aconteria se eu cedesse

Um pouco

Ao doce esquecimento profundo?

Não cairia o mundo.

Senta e se adormenta

\section{PLANCINA}

Cabelos de prata, sentido lento,

è grande martírio

Estão com os anos

Somente as angústias

E não o gozo.

Tabela 4 MINATO/SARTORIO, III/14, La Caduta di Elio Seiano. Veneza: Heredi Leni, 1667

As velhas amas de leite cômicas do repertório seiscentesco veneziano prenunciam toda uma série de personagens secundários com funçóes muito claras dentro das tramas operísticas. Da conexão entre personagens altos (através, por exemplo, do rufianismo ou simplesmente da entrega de cartas) ao desenlace de nós dramáticos ou ainda com a função de comic 
relief, estas velhas se demonstram, após uma análise profunda do corpus, personagens ainda mais complexos. Tanatos e Eros em um só corpo, o travestimento e o desejo latente, a sabedoria ancestral e a loucura. A memória, então, tem neste corpus uma função clara: gozar do presente através das lembranças ou (no caso das velhas mais moralistas) somente se entregar ao sofrimento causado pela passagem do tempo e das atuais impossibilidades de deleite. Como constata Rolanda Barthes em seu Fragmentos de um discurso amoroso: "je me souviens pour être malheureux/heureux - non pour comprendre" . Do ponto de vista dramatúrgico a anamnese da velha é o disparador do carpe diem e de toda pulsão vital, Eros se confronta com Thanatos e, pelo menos nas tramas libretísticas do século XVII veneziano, sai triunfante (e de gôndola).

\section{REFERÊNCIAS BIBLIOGRÁFICAS}

BARTHES, Roland. Fragments d'un discours amoureux. Paris: Éditions du Seuil, 1977.

BIANCONI, Lorenzo e Thomas Walker. Dalla Finta pazza alla Veremonda: Storie di febiarmonici. Rivista Italiana di Musicologia, Milano, v. 10, p. 380-454, 1975.

L'Ercole in Rialto. Venezia e il melodramma nel

Seicento. In: MURARO,

Maria Teresa, Firenze: Olschki, 1976, p. 259-272.

CAPOMACCHIA, Anna Maria. L'eroica nutrice. Sui personaggi 'minori' della scena tragica greca. Roma: Aracne, 1999. COSTA, Ligiana. 'Non per tutto l'età m'aggrinza': Le vecchie comiche nell'opera veneziana del Seicento. 313 p. Doutorado em Musicologia e Bens Culturais. Universidade François Rabelais de Tours e Universidade degli Studi di Torino, Tours, 2008.

FABBRI, Paolo. Diffusione dell'opera. Musica in scena I: Il teatro musicale dalle origini al primo Settecento, Torino: Utet, p. 105-127 (v. 8).

WALKER, Thomas. Gli errori di Minerva al tavolino; osservazioni sulla cronologia delle prime opere veneziane. In MURARO, Maria Teresa. Venezia e il melodramma nel Seicento, Firenze: Olschki, 1976, p. 7-20. 